\title{
Patterns of genotypic diversity in Czechoslovakian Daphnia
}

\author{
Paul D. N. Hebert* \\ Steven S. Schwartz $†$ and \\ Jaroslav Hrbacek $\ddagger \S$
}

\author{
* Department of Biological Sciences, University of \\ Windsor, Windsor, Ontario N9B 3P4, Canada. \\ $\uparrow$ Department of Biology, University of Houston, \\ Houston, Texas 77004, U.S.A. \\ $¥$ Institute of Landscape Ecology, Czechoslovakian \\ Academy of Sciences, Borivojova 35, CS 13000. \\ Praha 3, Czechoslovakia.
}

Patterns of allozyme diversity were studied in Czechoslovakian populations of six Daphnia species to ascertain their mode of reproduction, the incidence of interspecific hybrids, and the relationship between genotypic diversity and habitat permanency. All six species were shown to reproduce by cyclic parthenogenesis. $D$. pulex and $D$. pulicaria, two closely related species whose taxonomic validity has been questioned, showed little polymorphism but diagnostic gene substitutions confirmed their distinctiveness. Populations of the pond species $D$. magna and $D$. longispina were commonly polymorphic but showed infrequent Hardy-Weinberg deviations. $D$. galeata from pond habitats showed a moderate incidence of deviations, but reservoir populations showed consistent heterozygote excesses and non-random multilocus associations. $F_{1}$ hybrids and backcross progeny between $D$. longispina and $D$. galeata were detected in a third of the ponds and comprised, on average, 5 per cent of the local populations. In reservoirs, $F_{1}$ hybrids between $D$. galeata and $D$. cucullata were common, with a genotypically diverse group of hybrids dominating one site.

\section{INTRODUCTION}

Information on the genetic consequences of cyclic parthenogenesis has been largely derived from allozyme studies on aphids and cladocerans. Since most aphid taxa have low heterozygosity (Tomiuk and Wohrmann, 1980), much of the detailed information on the genetic response to cyclic parthenogenesis has come from work on cladocerans (Hebert, 1987). Allozyme surveys have shown that the gene pools of cladocerans are fragmented on a local scale with differentiation most pronounced in species from small habitats (Mort and Wolf, 1986). Genotypic frequencies in cladocerans from ephemeral ponds are ordinarily stable and in Hardy-Weinberg proportions. In permanent ponds, in contrast, genotypic frequencies often show large heterozygote excesses and, although these populations are not dominated by single clones (Young, 1979), linkage disequilibrium among variants at different loci is sufficiently common to make it clear that genotypic diversity is low. These habitat-related differences in genotypic structure have been linked to the oppor-

$\S$ Present address: Hekrova 820, CS 149 00, Praha 4, Czechoslovakia. tunity for long-term parthenogenetic reproduction in permanent ponds. Habitat permanency is, however, insufficient to ensure continued parthenogenesis; in some permanent habitats adults do not persist through the year and populations must be re-established from sexual eggs. The genotypic characteristics of such populations resemble those of cladocerans from ephemeral ponds (Hebert and Moran, 1980). The sole intensive study of cladocerans from lake habitats showed a genotypic structure typical of populations subject to substantial sexual recruitment. Specifically, genotypic frequencies were both stable and in Hardy-Weinberg equilibrium (Mort and Wolf, 1985; 1986). This might be explained by populations either failing to over-winter as adults or by the resident parthenogenetic populations being exposed to large inputs of sexual recruitment. There is clearly a need for further studies on the relationship between genotypic diversity in cladocerans and habitat permanency.

We aimed to extend understanding of the genetic response of cladocerans to varying habitat permanency by surveying populations of six Daphnia species common in reservoirs and fish ponds of central and southern Czechoslovakia. These species included $D$. magna, a member of the sub- 
genus Ctenodaphnia and a species which has been the subject of allozyme studies in both Britain (Hebert, 1974; Young 1979; Carvalho and Crisp, 1987) and Sweden (Korpelainen, 1984). Five members of the nominate subgenus were also examined including three members (longispina, galeata, cucullata) of the D. longispina group. An earlier study on German lakes showed a high incidence of hybrids between the latter two species (Wolf and Mort, 1986; Wolf, 1987). The final species pair (D. pulex and D. pulicaria) are two taxa whose distinctiveness has been uncertain. Populations of the six species were surveyed in two major habitat types-large semi-permanent ponds and reservoirs.

\section{MATERIALS AND METHODS}

Daphnia populations were sampled from 35 sites in central and southern Bohemia (fig. 1). Five of the sites were lowland reservoirs, 27 were fish ponds and three were temporary pools. The thirty smaller habitats were located in five areas; fourteen

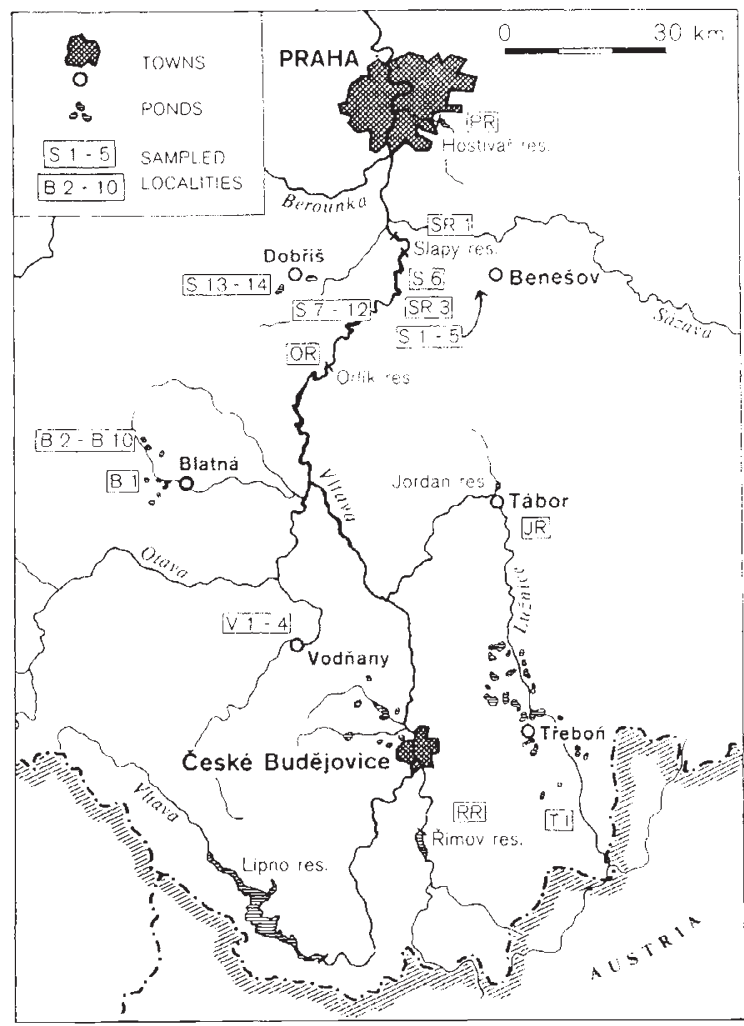

Figure 1 Locations of the five reservoirs and 30 fish ponds/ pools from which Daphnia were collected. fish ponds were sampled near the Slapy reservoir south of Prague, nine near Blatna, and four near Vodnany all in southern Bohemia. Single pools were sampled near Prague, Blatna and Trebon. Throughout the paper individual habitats are identified using the acronyms shown in brackets behind each site name. The fish ponds from the Slapy area included Novy Pod Neveklovem (S1), Mnichovec (S2), Necky (S3), Farsky (S4), Pansky Pod Plockovem (S5), Blazim (S6), Horni (S7), Dolni (S8), Zaborne Lhote, Mnich Pod Zabornou Lhotou (S9), Cimsky (S10), Mokrsko (S11), Krenicna (S12), Strz (S13) and Dobris (S14). The fish ponds from the Blatna region included Nadrz v Zabori (B1), Vitanovske Jezarko (B2), Radov (B3), Kupcov (B5), Vitanov (B6), Hadi (B7), Zoldanka (B8), Stary Palenec (B9), and Velky Palenec (B10). The fish ponds near Vodnany included fish pond $\mathrm{Nr}$. 37 in the Experimental Station (V1), Kacirek (V2), Dremliny (V3), and Strbssky (V4). Single pools were also sampled near the Radov dam (B4), south of Trebon (T1), and near the Hostivar reservoir on the south eastern margin of Prague (P1). The reservoirs sampled included Slapy near Zivohost (SR1), and Cholin bridges (SR3), Orlik near the dam (OR), Rimov near the dam (RR), Jordan (JR) and Hostivar (PR). Large lowland reservoirs are a recent introduction to Czechoslovakia with most established over the past 30 years. Jordan Reservoir is exceptional as it was established in the 15 th Century. By contrast, the majority of fish ponds were constructed more than 400 years ago and some date to the tenth century (Hrbacek, 1984). The reservoirs have remained filled with water since construction, but fish ponds are drained at 1-2 year intervals. The ponds are ordinarily refilled within a few days of drainage and, even while empty, some pools up to $0.5 \mathrm{~m}$ remain in the basin. As a consequence of these residual pools and water transfer between ponds, it seems likely that cladocerans in these habitats may reproduce parthenogenetically for extended periods of time.

With the exception of the Rimov reservoir which was also collected in May 1987, the collections from natural habitats were made between 18 August and 10 September 1985. Animals were ordinarily electrophoresed within $24-48 \mathrm{~h}$ of collection. The electrophoretic phenotype of each individual was determined at 6 enzyme locialdehyde oxidase $(A o)$, amylase $(A m y)$, glutamate oxalacetate transaminase (Got), lactate dehydrogenase $(L d h)$, phosphoglucose isomerase $(P g i)$, and phosphoglucomutase $(\mathrm{Pgm})$. These enzymes were chosen for routine study because they are commonly polymorphic and produce phenotypes 
whose genetic basis is well understood. Alleles were numbered in order of mobility, with the highest number for the allele with the greatest mobility. Electrophoresis was carried out on Titan III cellulose acetate gels using methods similar to those described in Hebert and Payne (1985). The use of cellulose acetate electrophoresis permitted the resolution of all six enzymes on single individuals of even the smallest species, $D$. cucullata.

Populations were sampled with vertical tows of a $30 \mathrm{~cm}$ diameter plankton net $(200 \mu \mathrm{m}$ mesh). Daphnia were identified using Hrbacek (1959) and Scourfield and Harding (1966). Sample sizes ordinarily ranged from 24-96 and were smaller only when a particular species was rare in the habitat. Gene frequencies were determined by direct count. Genotypic frequencies at polymorphic loci were compared with Hardy-Weinberg expectations if the frequency of the most common allele was less than 0.90 and the sample size was greater than 20 . The divergence in genotypic frequencies between conspecific populations was assessed using a $G$-statistic, employing Yates' correction for small sample size. Gene frequency divergence among conspecific populations was quantified by calculating inbreeding coefficients $\left(F_{\mathrm{ST}}\right)$ due to population subdivision (Nei, 1977).

\section{RESULTS}

\section{Species distributions}

D. magna was present in seven fish ponds and one pool and $D$. pulex in three fish ponds and one pool, but neither was detected in the reservoirs (table 1). D. pulicaria and D. longispina were similarly common in fish ponds and pools, but both were also rarely found in reservoirs. $D$. galeata was the most common taxon in both pond and reservoir habitats, while $D$. cucullata, the rarest species, was limited to reservoirs.

Table 1 Distribution of five Daphnia species in 30 fish ponds/pools and five reservoirs in Czechoslovakia

\begin{tabular}{lll}
\hline & Fish ponds/pools & Reservoirs \\
\hline D. magna & 8 & 0 \\
D. pulex & 4 & 0 \\
D. pulicaria & 13 & 2 \\
D. longispina & 10 & 1 \\
D. galeata & 19 & 4 \\
D. cucullata & 0 & 2 \\
\hline
\end{tabular}

\section{Allozyme variation in D. magna}

The eight populations of $D$. magna were monomorphic at $L d h, A m y$ and $A o$, but diallelic polymorphisms were detected at $\mathrm{Pgi}$, Got and $\mathrm{Pgm}$ (table 2). For 11 of 13 cases, genotypic frequencies were in Hardy-Weinberg equilibrium. The two deviations arose from large heterozygote excesses. Genotypic frequencies at each of the three loci were significantly heterogeneous among populations (Pgi $G_{14}=305$, Got $G_{14}=322, P g m G_{14}=185$, all $P<0 \cdot 001)$. Inbreeding coefficients due to population subdivision ranged from 0.172 to 0.379 and averaged $0 \cdot 245$.

Table 2 Gene and genotypic frequencies at three polymorphic loci in eight populations of Daphnia magna

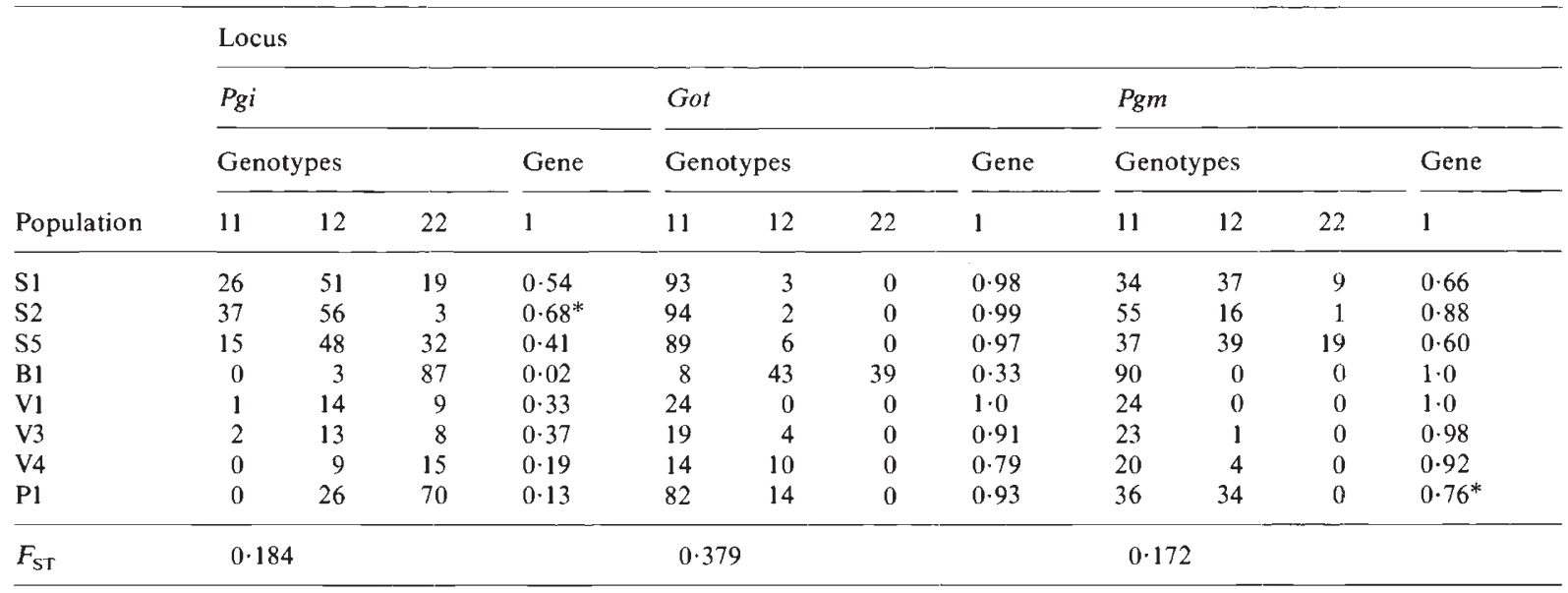

\footnotetext{
* Significant $(P<0 \cdot 01)$ deviation from Hardy-Weinberg expectations.
} 


\section{Allozyme variation in the $D$. pulex group}

Populations of both $D$. pulex and $D$. pulicaria showed little variation. All $12 \mathrm{D}$. pulicaria populations were invariant at $L d h$, Got and $P g m$ and shared the same common allele at these loci with D. pulex. Rare variation was detected at two of these loci in $D$. pulex. Of $14 D$. pulex from S3 one was heterozygous for a unique slow allele at $\mathrm{Pgm}$ and 7 of 25 individuals from S5 were heterozygous for a faster allele at $L d h$. Aldehyde oxidase varied in both species, but allelic variants were too poorly separated to score reliably, although AO phenotypes generally ran faster in $D$. pulex than in $D$. pulicaria. At the two remaining loci there were diagnostic differences between the taxa (table 3). At both Pgi and Amy D. pulex was nearly monomorphic, D. pulicaria was weakly polymorphic, and the two species shared no alleles. Hybridization between the species was rare as only 1 of the 613 individuals analyzed appeared to be a $F_{1}$ hybrid. It was obtained from the $S 1$ population and was heterozygous for the appropriate alleles at Pgi, Amy, and Ao.

\section{Allozyme variation in the $D$. longispina group}

Polymorphisms were detected in each of the three taxa belonging to this group. D. longispina was commonly polymorphic at Pgm and Got but rarely variable at $P g i$ and $A m y$. Most $D$. galeata populations were polymorphic at Pgm and Amy and some were variable at $P g i$. The only population of $D$. cucullata providing a large sample was variable at Pgm, Pgi and Amy.

Only a single $P g i$ allele was detected in the Blatna populations of $D$. longispina (table 4). The same allele was common in the Slapy and Vodnany regions but two additional rare alleles were also detected. At Got there were two common alleles in each area and a third rare allele. One amylase allele was close to fixation in all populations but three rare alleles were found fairly widely. At $\mathrm{Pgm}$ five alleles were detected, with the same two alleles common at each site. Among the 15 polymorphisms (seven at Got and Pgm, one at Pgi) tested, none showed a significant devation from HardyWeinberg expectations. Populations of $D$. longispina showed limited gene frequency differences with $\mathrm{F}_{\mathrm{ST}}$ averaging only 0.054 .

D. galeata was monomorphic for allele 3 of $G o t$, which was the second commonest allele in $D$. longispina. D. galeata was highly polymorphic at Pgm (table 5). Its populations shared some alleles at this locus with $D$. longispina, although alleles 1 and 2 were much commoner in D. galeata. At Pgi, the species shared the same common and two rare alleles but several $D$. galeata populations possessed a unique fast allele. Finally, at amylase, D. galeata was polymorphic for two alleles which were very rare in $D$. longispina. Allele frequencies at each of the loci showed significant variation among local populations. For example, among the 8 populations from the Slapy area there was significant variation in genotypic frequencies at the

Table 3 Genotypic frequencies in four populations of $D$. pulex and 12 populations of $D$. pulicaria at two loci showing diagnostic differences between the taxa

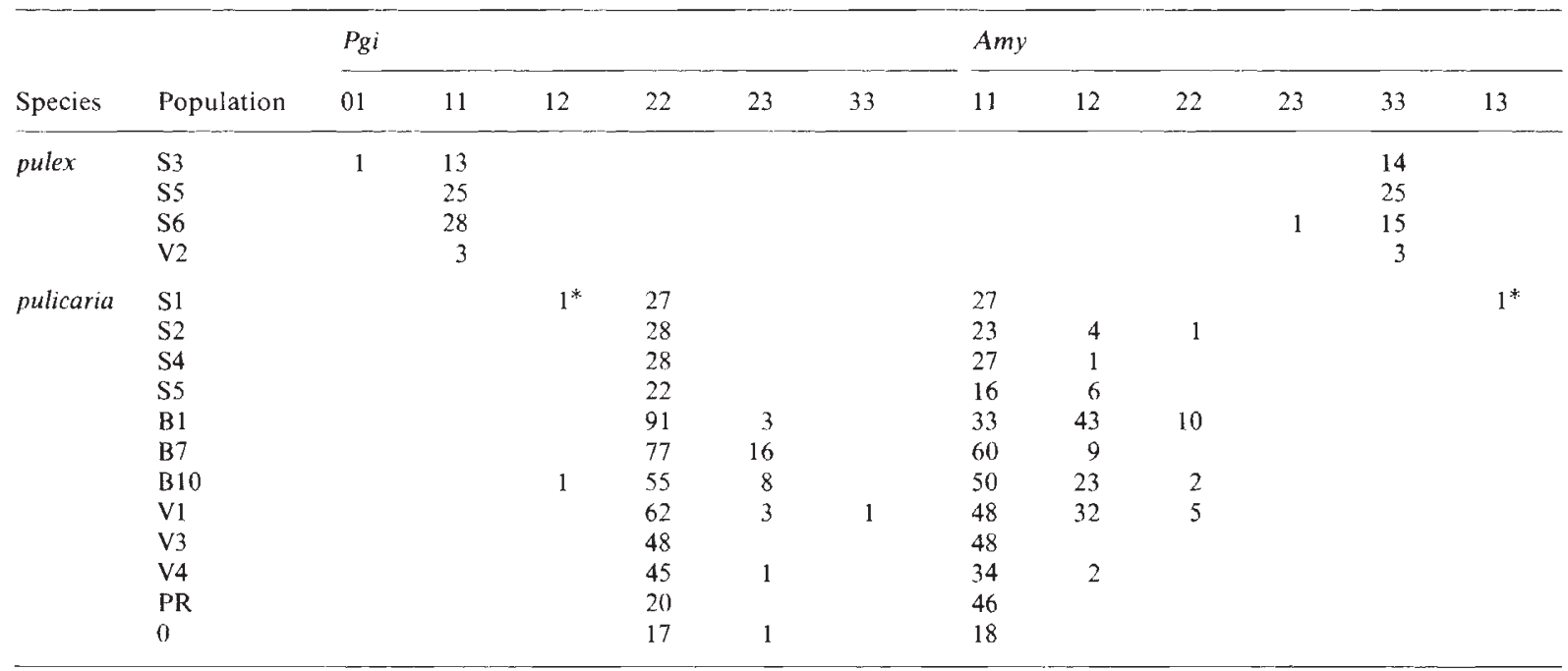

\footnotetext{
* Same individual, putative $F_{1}$ hybrid.
} 
Table 4 Allele frequencies at 4 loci in 9 populations of $D$. longispina

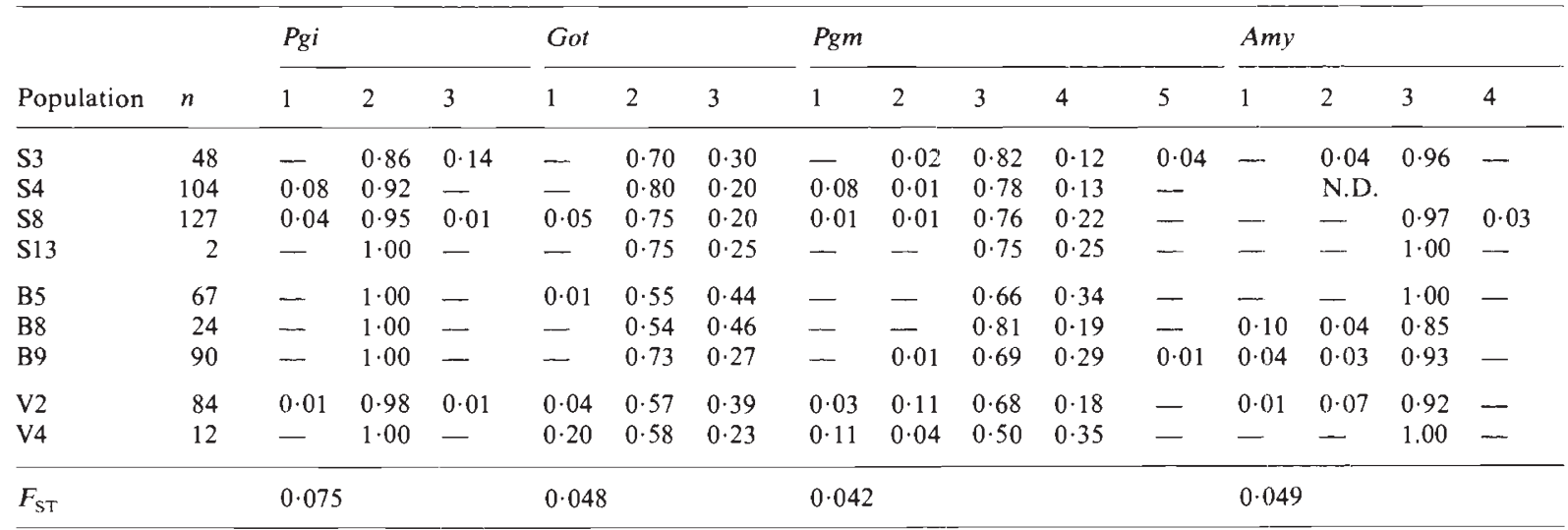

* Significant $(P<0.05)$ deviations from Hardy-Weinberg equilibrium.

$\operatorname{Pgm}\left(G_{21}=129\right), \operatorname{Pgi}\left(G_{35}=418\right)$, and $\operatorname{Amy}\left(G_{10}=\right.$ 116) loci (all $P<0 \cdot 001$ ). When all populations were considered, inbreeding coefficients ranged from $0 \cdot 076$ to $0 \cdot 222$ and averaged $0 \cdot 136$. Pond populations of $D$. galeata showed a moderate incidence of Hardy-Weinberg deviations (5 of the 13 populations polymorphic at $\mathrm{Pgm}, 1$ of 11 at $A m y$, and zero of four at $P g i$ ) with an equal proportion of the deviations due to heterozygote deficiency as to excess. The incidence of HardyWeinberg deviations was much higher in reservoir populations of D. galeata. Each of the three reservoir populations was polymorphic at $\mathrm{Pgm}$ and Amy and all showed deviations. At Pgi two of the three populations were polymorphic and again both showed deviations. Seven of the eight deviations were associated with heterozygote excess. In both reservoir and pond populations showing

Table 5 Gene frequencies at three polymorphic loci in 19 pond and three reservoir populations of $D$. galeata

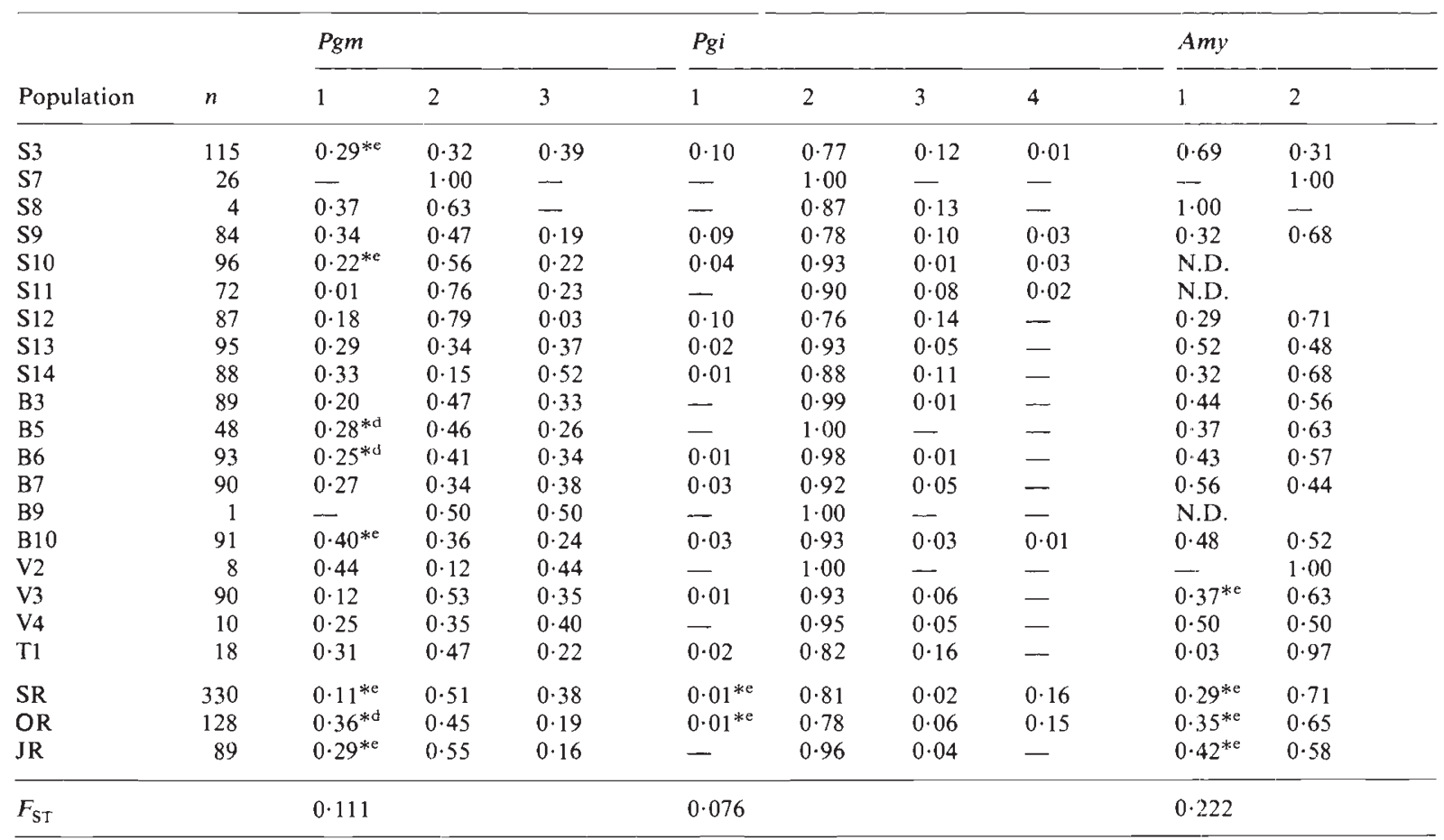

* Significant $(P<0.05)$ deviations from Hardy-Weinberg equilibrium. $\mathrm{d}=$ het deficiency, $\mathrm{e}=$ het excess. 
Table $6 G$-test of association between genotypes at the Pgi and Pgm loci in populations of D. galeata from three sites

\begin{tabular}{|c|c|c|c|c|c|c|}
\hline \multicolumn{4}{|c|}{ Slapy Reservoir } & \multicolumn{2}{|c|}{$P g m$} & \multirow[t]{2}{*}{$G$} \\
\hline Genotypes & 44 & 33 & 34 & 23 & $22 / 24$ & \\
\hline$P g i$ & 14 & 44 & 116 & 24 & 10 & \\
\hline 24 & 18 & 13 & 43 & 24 & 5 & $G_{4}=18 \cdot 3$ \\
\hline \multicolumn{4}{|c|}{ Orlik Reservoir } & \multicolumn{3}{|c|}{ Pgm } \\
\hline Genotypes & 44 & 33 & 34 & 23 & $22 / 24$ & \\
\hline \multirow{2}{*}{$\begin{array}{ll}P g i & 22 \\
& 24\end{array}$} & 7 & 35 & 12 & 1 & 7 & \\
\hline & 2 & 2 & 14 & 13 & 2 & $G_{4}=42 \cdot 9$ \\
\hline \multicolumn{2}{|l|}{ Slapy 3} & \multicolumn{3}{|c|}{$P g m$} & & \\
\hline Genotypes & 44 & $24 / 34$ & $22 / 33$ & 23 & & \\
\hline \multirow{3}{*}{$\begin{array}{ll}P g i & 22 \\
& 23 \\
& 12\end{array}$} & 1 & 4 & 8 & 31 & & \\
\hline & 16 & 6 & 0 & 0 & & \\
\hline & 3 & 11 & 2 & 1 & & $G_{6}=77 \cdot 8$ \\
\hline
\end{tabular}

Hardy-Weinberg deviations there were strong non-random associations between genotypes at different loci (table 6). The patterns of association varied between sites. For example, at Slapy Reservoir most $D$. galeata homozygous at Pgi were also Pgm 34 heterozygotes, while at Orlik Reservoir most were Pgm 33 homozygotes.

\section{Hybridization among members of the $D$. longispina group}

While all three species shared the same $L d h$ allele, differences between the species were evident at several other loci. D. longispina was most readily discriminated from $D$. galeata and $D$. cucullata by gene substitutions at Ao and Amy. Ao was polymorphic in all three taxa but intraspecific variants were difficult to discriminate because of their small mobility differences and were hence treated as single phenotypes. However, the Ao alleles in $D$. galeata and $D$. cucullata produced proteins which migrated much farther than those in $D$. longispina. Conversely at amylase the two former species were polymorphic for alleles producing less mobile products than the allele which was close to fixation in $D$. longispina. D. cucullata was easily separated from both $D$. galeata and $D$. longispina by its unique slow allele at Pgi. Variation at Got was also useful in species discrimination. D. galeata was monomorphic for a fast allele, while $D$. cucullata was homozygous for a very slow allele. $D$. longispina was polymorphic for 3 alleles of which the fastest was shared with $D$. galeata.

The presence of diagnostic gene substitutions between each species pair made it possible to assess the incidence of hybridization. $F_{1}$ hybrids between $D$. galeata and $D$. longispina were recognized by their heterozygosity at $A o$ and their possession of a 13 or 23 phenotype at $A m y$ and a 23 or 33 phenotype at Got. Heterozygotes between D. cucullata and $D$. galeata were recognized from their heterozygosity for the appropriate alleles at Got and $P$ Pi.

Hybrids between $D$. galeata and $D$. cucullata were detected only in reservoir habitats. A random sample of 332 individuals from several sites in the Slapy Reservoir revealed only two $F_{1}$ hybrids; the remainder were $D$. galeata. The hybrids were morphologically distinct as each of three "D. galeata", chosen for analysis because of their atypical pointed helmet, were hybrids. There was no evidence of either backcrosses between the hybrids and either parent species or of hybrid self-fertilization, for all putative hybrids were heterozygous at both diagnostic loci. Despite their rarity, the Slapy hybrids were not uniclonal. Variation at $\mathrm{Pgm}$ and $A m y$ revealed that there were three clones among the five hybrids. Results from the Jordan Reservoir were similar to those at Slapy; $D$. galeata was again the dominant taxon and only one $D$. cucullata and one hybrid were detected in a sample of 96 individuals. Hybrids were apparently absent from the Hostivar Reservoir which contained only D. cucullata and the Orlik Reservoir which contained only $D$. galeata. In contrast to these cases, the September 1985 sample from the Rimov Reservoir contained only $F_{1}$ hybrids between $D$. galeata and $D$. cucullata. Eighteen different clones were represented among the 83 individuals analysed, with two clones making up nearly half the total. 


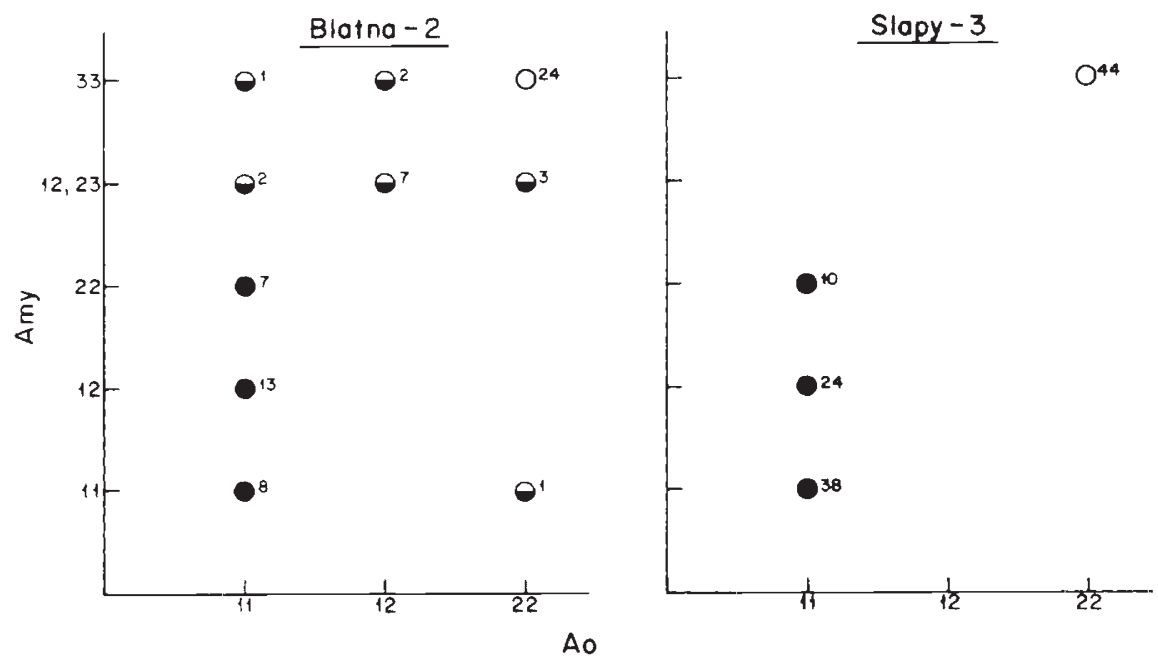

Figure 2 Numbers of individuals with particular dilocus genotypes in two habitats where D. galeata and $D$. longispina cooccurred. $=$ galeata $\mathrm{O}=$ longispina $;, \mathrm{F}_{1}$ hybrids, backcross.

When this site was reanalysed in May 1987, only 2 per cent of the population were hybrids, with $D$. galeata making up the remainder.

The presence of two diagnostic loci (Amy, Ao) permitted an assessment of the extent of introgressive hybridization between $D$. galeata and $D$. longispina. In most populations individuals were readily classified either as members of the parent species (e.g., Slapy 3 , fig. 2 ) or more rarely as $F_{1}$ hybrids. However, these were exceptions. The B4 population consisted almost exclusively of two genotypes. One clone was homozygous for alleles typical of D. longispina. The second was heterozygous for alleles at Got and Amy, suggesting hybridization with $D$. galeata, but homozygous for the $A o$ allele typical of $D$. longispina, suggesting that this clone had arisen via a backcross to that species. The situation at B2 was more complicated with the population containing both parent species, $F_{1}$ hybrids and backcrosses (fig. 2).
The analyses of fish ponds revealed that hybrids between $D$. galeata and D. longispina were broadly distributed, although generally rare (table 7 ). Among the 14 ponds from the Slapy area, five lacked members of the $D$. longispina group, five contained only $D$. galeata, two only $D$. longispina and the species co-occurred at S3. No hybrids were detected at the latter site but a single hybrid was observed in S8 which was dominated by $D$. longispina (table 7). Members of the D. longispina group were present in nine of the ten Blatna fish ponds and pools, with the taxa co-occurring at three sites, galeata alone at four sites, and longispina at two sites. Hybrids and backcross individuals were present in the B2 and B5 ponds, where both parent species occurred at high frequency, but were absent from B9 where $D$. longispina was predominant. Pond B7 contained both $D$. galeata and a low incidence of $F_{1}$ hybrids, while $B 4$ was, as already noted, dominated by a single clone which appeared

Table 7 Proportions of $F_{1}$ hybrids and backcrosses at six ponds where $D$. galeata and $D$. longispina co-occur and at three additional ponds containing only one parent species

\begin{tabular}{lrllll}
\hline Pond & $n$ & Longispina & Galeata & $\mathrm{F}_{1}$ hybrids & Backcross \\
\hline S3 & 163 & 0.29 & 0.71 & - & - \\
B2 & 66 & 0.44 & 0.30 & 0.11 & 0.15 \\
B5 & 135 & 0.36 & 0.50 & 0.09 & 0.05 \\
B9 & 90 & 0.99 & 0.01 & - & - \\
V2 & 96 & 0.93 & 0.03 & 0.05 & - \\
V4 & 24 & 0.54 & 0.42 & 0.04 & - \\
S8 & 96 & 0.99 & - & 0.01 & - \\
B4 & 92 & 0.15 & - & - & 0.05 \\
B7 & 92 & - & 0.99 & 0.01 & - \\
\hline
\end{tabular}


to be a backcross. This pool was both the smallest and most eutrophic site sampled. A low incidence of $F_{1}$ hybrids was also present in the two ponds from the Vodnany region where both parent species occurred. Pooling data from all regions, $F_{1}$ hybrids and backcross individuals were found in four of six ponds where both parent species occurred, in 1 of 11 ponds with only $D$. galeata, and in two of four ponds with only $D$. longispina.

\section{DISCUSSION}

Previous allozyme studies on Eurasian members of the $D$. pulex group have focused on a study of environmental factors affecting enzyme phenotype (Ruvinsky et al., 1983) and involved only limited population surveys. The taxonomy of the group remains unsettled. There has been a reluctance to accept the distinctiveness of $D$. pulex and D. pulicaria (Brooks, 1957; Scourfield and Harding, 1966). The present study has, however, confirmed Hrbacek's (1959) assertion that the two taxa are distinct. Specifically diagnostic allele substitutions were present at both Pgi and Amy. Moreover, at sites where both species occurred, hybrid individuals were either rare or absent. The Czechoslovakian populations of both species showed little allozyme variations, contrasting with the abundance of allozyme variation at the same loci in North American populations (Hebert et al., 1988). If all European populations prove to be equally invariant, it suggests that both taxa experienced a population bottleneck perhaps reflecting a recent colonization of Europe or a rapid expansion from small populations which survived the Pleistocene. The general lack of variation made it difficult to determine the breeding system employed by these species, which is of interest as North American D. pulex show a varied reproductive behaviour-some clones reproduce by cyclic parthenogenesis, while others are obligate parthenogens (Hebert and Crease, 1983; Lynch, 1983; Innes et al., 1986). None of the Czechoslovakian populations showed the fixed heterozygosity typical of obligate asexuals, suggesting that both species reproduce by cyclic parthenogenesis.

Information on the genotypic characteristics of lake cladocerans derives largely from work on the daphniid fauna of a group of shallow lakes in northern Germany (Mort and Wolf, 1985; 1986). These lakes are dominated by three members of the $D$. longispina group $-D$. cucullata, $D$. galeata and D. hyalina. Mort and Wolf $(1985 ; 1986)$ showed that genotypic frequencies in populations of each species were ordinarily in Hardy-Weinberg equilibrium. This result was surprising as earlier work had shown pronounced Hardy-Weinberg deviations and non-random associations of genotypes at different loci in populations of $D$. magna from permanent habitats (Hebert, 1974; Young, 1979; Carvalho and Crisp, 1987). The studies on German lake Daphnia and earlier work on Australian species (Hebert and Moran, 1980) indicated that habitat permanency was not a sufficient condition for the development of such deviations. Hebert (1987) suggested that habitat permanency must be coupled with a low incidence of sexual recruitment. The present study has shown variation in the incidence of Hardy-Weinberg deviations among taxa from a single habitat type. Thus, among fish pond populations, Hardy-Weinberg deviations were not observed in $D$. longispina, were rare in $D$. magna, but reasonably common in $D$. galeata. These differences may be a consequence of different responses by the species to the regular drainage of these habitats. The sexual eggs of $D$. longispina might, for example, be more prone to hatch following desiccation than those of D. galeata. Our study also revealed a difference between the genotypic structure of $D$. galeata from fish ponds and reservoirs, with the latter showing both more frequent deviations and heterozygote excess. The more stable conditions in reservoirs may permit the year-round persistence of large parthenogenetic populations, whose genotypic diversities are supplemented by sexual recruitment on an irregular basis. The genotypic structure of D. galeata in Czechoslovakian reservoirs clearly differs from that in German lakes, and reveals that populations of this species do, under appropriate conditions, develop the genotypic structure characteristic of permanent populations of $D$. magna. There is a clear need for broader surveys of lake cladocerans to identify the taxonomic and ecological correlates with the emergence of such genotypic structure.

Mort and Wolf (1986) found that variation in allele frequencies among lake populations of $D$. galeata, as measured by inbreeding coefficients $\left(F_{\mathrm{ST}}\right)$, was less pronounced than that in populations of several Daphnia species from small ponds $(0 \cdot 05-0 \cdot 10$ vs. $0 \cdot 20-0 \cdot 50)$. Mort and Wolf (1986) attributed the lower level of differentiation in lake habitats to larger founder populations and more extensive gene flow. It is perhaps equally possible that observed levels of gene frequency differentiation do not represent equilibrium values. Allendorff and Phelps (1981) note that the erosion of gene frequency differences among populations can 
require thousands of generations when gene flow is modest. In such cases the level of gene frequency divergence can be linked more closely to the age of the population than to the initial level of gene frequency divergence or extent of gene flow. It seems likely that Daphnia populations from small ponds are generally more recently founded than those in lakes, and hence the pattern of gene frequency divergence is concordant with the expectations of Allendorff and Phelps' (1981) model. Our study has, however, shown a rather low level of differentiation among Daphnia populations from fish ponds, despite the fact that such populations must be less than 500 years of age. Moreover, the level of differentiation varied among taxa, with gene frequency differences smallest among populations of $D$. longispina and greatest in D. magna.

Wolf and Mort (1986) surveyed the incidence of hybrids among three members of the $D$. longispina group in 18 German lakes. Hybrids between D. hyalina and D. cucullata were rare, but the other species pairs regularly hybridized. Hybrids between $D$. galeata and $D$. hyalina were, for example, noted in seven of nine lakes in which these species co-occurred with hybrids comprising, on average, 34 per cent of the populations. Hybrids were also detected in four of six lakes where $D$. galeata and D. cucullata co-occurred, although hybrids were much less common in this case, (mean $=3$ per cent). Our study has shown that these latter two species also hybridize in Czechoslovakia and revealed a population which was transitorily dominated by a genotypically diverse hybrid swarm. Few hybrids between $D$. galeata and D. longispina were also detected in many fish ponds and their genotypic diversity indicated that they had arisen from a number of hybridization events. The joint results of this study and earlier work (Wolf and Mort, 1986; Wolf, 1987) suggests that $D$. galeata regularly hybridizes with all other members of the D. longispina group. By contrast, D. cucullata and $D$. hyalina rarely hybridize with each other, and perhaps never hybridize with $D$. longispina. $D$. galeata may, however, serve as a conduit for the exchange of genes between the lake taxa and $D$. longispina, as both $\mathrm{F}_{1}$ and backcross progeny were observed between $D$. galeata and D. longispina. One would expect that, as a result of its frequent hybridization, D. galeata should show both enhanced allozymic diversity and signs of mitochondrial DNA leakage from its sister taxa.

In summary, our work has supported the genetic distinctiveness of the species recognised by earlier taxonomic study and provided no evidence of additional species. Each of the species appeared to reproduce by cyclic parthenogenesis. Genotypic frequencies in Daphnia populations from fish ponds were ordinarily in Hardy-Weinberg equilibrium, suggesting that these populations are exposed to regular recruitment from sexual eggs. By contrast, reservoir populations showed a high incidence of Hardy-Weinberg deviations and a genotypic structure reminiscent of permanent populations of D. magna. In these sites adults must overwinter in a motile diapause and sexual recruitment must be small. Interspecific hybridization was observed among members of the $D$. longispina group and between $D$. pulicaria and D. pulex, although hybrids were generally rare.

Acknowledgements Funding for this project was provided to PDNH by an operating grant from the Natural Sciences and Engineering Research Council of Canada as well as by a Bilateral Exchange Award from NSERC and the Czechoslovak Academy of Sciences. Drs Z. Brandl, H. Fernando and V. Korcinek kindly assisted in the collection of samples.

\section{REFERENCES}

ALLENDORFF, F. W. AND PHELPS, S. R. 1981. Use of allelic frequencies to describe population structure. Can. J. Fish. Aquat. Sci., 38, 1507-1514.

BRoOKS, J. L. 1957. The Systematics of North American Daphnia. Mem. Conn. Acad. Arts Sci., 13, 5-180.

CARVAlHO, G. R. AND CRISP, D. J. 1987. The clonal ecology of Daphnia magna (Crustacea:Cladocera). I. Temporal changes in the clonal structure of a natural population. $J$. Anim. Ecol., 56, 453-468.

HEBERT, P. D. N. 1974. Enzyme variability in natural populations of Daphnia magna. II. Genotypic frequencies in permanent populations. Genetics, 77, 323-334.

HEBERT, P. D. N. 1987. Genotypic characteristics of cyclic parthenogens and their obligately asexual derivatives. In Stearns, S. C. (ed.) The Evolution of Sex and its Consequences. Birkhauser Verlag, Basel.

HEBERT, P. D. N. AND CREASE, T. J. 1983. Clonal diversity in populations of Daphnia pulex reproducing by obligate parthenogenesis. Heredity, 51, 353-369

HEBERT, P. D. N. AND MORAN, C. 1980. Enzyme variability in natural populations of Daphnia carinata King. Heredity, $45,313-321$

HEBERT, P. D. N. AND PAYNE, W. J. 1985. Genetic variation in populations of the hermaphroditic flatworm Mesostoma lingua (Turbellaria, Rhabdocoela). Biol. Bull., 169, 143151.

HEBERT, P. D. N., WARD, R. D. AND WEIDER, L. J. 1988. Clonaldiversity patterns and breeding systern variation in Daphnia pulex, an asexual-sexual complex. Evolution, 42, 147-159.

HRBACEK, J. 1959. Uber die angebliche Variabilitat von Daphnia pulex. L. Zool. Anz., 162, 116-126.

HRBACEK, J. 1984. Bohemian and Moravian Ponds. Ctk, Prague.

INNES, D. J., SCHWARTZ, S. S. AND HEBERT, P. D. N. 1986. Genotypic diversity and variation in mode of reproduction among populations in the Daphnia pulex group. Heredity, $57,345-355$. 
KORPELAINEN, H. 1984. Genic differentiation of Daphnia magna populations. Hereditas, 101, 209-216.

LYNCH, M. 1983. Ecological genetics of Daphnia pulex. Evolution, 37, 358-374.

MORT, M. A. AND WOLF, H. (3. 1985. Enzyme variability in large-lake Daphnia populations. Heredity, 55, 27-36.

MORT, M. A. AND WOLF, G. H. 1986. The genetic structure of large-lake Daphnia populations. Evolution, 40, 756-766.

NE1, M. 1977. F-statistics and analysis of gene diversity in subdivided populations. Ann. Hum. Genet., 41, 225-233.

RUVINSKY, A. O., LOBOV, Y. I. AND BELYAEV, I). K. 1983. Spontaneous and induced activation of genes affecting the phenotypic expression of glucose-6-phosphate dehydrogenase in Daphnia pulex. I. Intraclonal variation in the electrophoretic mobility of G6PDH. Mol. Gen. Genetics., $189,485-489$.
SCOURrield, D. J. AND HARDing, J. P. 1966. A Key to the British Freshwater Cladocera. Freshwater Biological Assoc. TOMIUK, J. AND WOHRMANN, K. 1980. Enzyme variability in populations of aphids. Theoret. Appl. Genet., 57, 125-127.

WOIF, H. G. 1987. Interspecific hybridization between Daphnia hyalina, D. galeata and D. cucullata and seasonal abundances of these species and their hybrids. Hydrobiologia, $145,213-217$.

WOLF, H. G. AND MORT, M. A. 1986. Interspecific hybridization underlies phenotypic variability in Daphnia populations. Oecologia, 68, 507-511.

YOUNG, J. P. W. 1979. Enzyme polymorphism and cyclic parthenogenesis in Daphnia magna. I1. Evidence of heterosis. Genetics, 92, 971-982. 